\title{
Different Pla Grafting Techniques on Chitosan
}

\author{
Nugraha Edhi Suyatma • Alain Copinet • \\ Estelle Legin-Copinet • Florence Fricoteaux • \\ Véronique Coma
}

Published online: 14 December 2010

(C) The Author(s) 2010. This article is published with open access at Springerlink.com

\begin{abstract}
PLA grafting on chitosan has been successfully prepared with two different methods: a direct grafting method and the ROP method. The thermal properties showed that the copolymerization of PLA on the chitosan's chain by direct grafting is more thermostable than the one obtained by the ROP method.
\end{abstract}

Keywords Chitosan · PLA · Grafting · Copolymerization

\section{Introduction}

Chitosan is a natural polymer derived from chitin which arouses a lot of interest because of its biodegradability, biocompatibility and its bacteriostatic and fungistatic properties. This material is film-forming and is used to manufacture films without using any additive. More over, the chitosan film has good barrier properties against gas and good mechanical properties (except elasticity). Thanks to these qualities, several studies have been launched on the possible applications of chitosan, to preserve or to

\section{N. E. Suyatma · A. Copinet $(\bowtie) \cdot$ F. Fricoteaux} GRESPI (Groupe de Recherche en Sciences Pour l'Ingénieur), Esplanade Roland Garros, Pôle Technologique Henri Farman, BP1029, 51686 Reims Cedex 2, France

e-mail: alain.copinet@univ-reims.fr

\section{E. Legin-Copinet}

LMI (laboratoire de Microbiologie Industrielle), Moulin de la Housse, 51686 Reims, France

e-mail: estelle.copinet@univ-reims.fr

\section{Coma}

Laboratoire de Chimie des Substances Végétales, Centre de Recherche en Chimie Moléculaire (CRCM), Université Bordeaux 1, 351, cours de la libération, F33405 Talence, France extend shelf life from some fresh products, such as fruits and vegetables, meat, and seafood. These studies show that it is possible to use chitosan as an active packaging material. However, there are some limitations. Indeed, it is steam sensitive due to its ability to form a big number of hydrogen bonds (two hydroxyl functions and one amine function in each motif repetition); it is also hard or brittle, and it needs to be associated to another polymer to overcome this kind of problem. That's why some chemical modifications are interesting techniques to make the chitosan compatible with other polymers. Among the possible solutions, the copolymerization method by grafting may be one of the best methods to combine synthetic polymers with chitosan. In the literature, polymer grafting on the chitosan's chains has been widely studied, for example the poly (methyl methacrylate) [1], the polyacrylamide [2], the poly (ethylene-glycol) [3], [4], [5], the poly (vinyl alcohol) [6], the polyacrylonitrile [7] and the poly(vinyl acetate) [8]. More over, a $\mathrm{pH}$-fluctuation sensitive hydrogel has been synthesized [9] by direct grafting of D, L-lactic acid on chitosan without using any catalyst. Besides, with the Ring Opening Polymerization method (ROP), L-Lactide has been employed [10] to synthesize chitin-grafted-PLA copolymers.

In this survey, the copolymerization by poly (lactic acid) grafting on chitosan's chains has been done, with the method described in [9] and [10]; some modifications have been brought in the solvent system and in the catalyst's use. This work aims at synthesizing and characterizing the chitosan-grafted-PLA copolymers thanks to two different methods. The first method is direct grafting (DG) of D,Llactic acid on chitosan by using para toluene sulfonic acid as a catalyst. The second method is the Ring Opening Polymerization method (ROP) of L-lactide by using triethylamine (TEA) as an activator $(\mathrm{H}+$ selective sensor). In the 
future, such chitosan-grafted-PLA copolymers could be used directly as a packaging material or as compatibilizing agent in the chitosan/PLA mixtures. The Infrared Heterodyne Spectroscopy (IRTF), the Differential Scanning Calorimetry (DSC) and the solubility test methods have been employed to characterize the grafted copolymers.

\section{Materials and Methods}

Materials

The chitosan used was a commercial material obtained from shrimp shell (Les Pêcheries Marinard Ltd., Canada). Its degree of deacetylation was $80-85 \%$, determined by a colloidal method. D, L-Lactide used was a commercial material obtained from Sigma-Aldrich (USA).

\section{Sample Preparation}

PLA grafting on chitosan.

Two different methods have been used:

- The Ring Opening Polymerization method (ROP) of L-lactide, in order to graft PLA on the chitosan's chain,

- The direct grafting method (DG) using the D,L-lactic acid monomer.

Figure 1 shows the PLA-grafting process on the chitosan's chain by the Ring Opening Polymerization method. The chitosan $(1.0 \mathrm{~g})$ has been put in $300 \mathrm{ml}$ of $1 \%$ acetic acid. We have filtered the solution, put it into a reactor
$(500 \mathrm{ml})$ and purged it with nitrogen during a $30 \mathrm{~min}$ period. After that, the L-lactide ( $4.0 \mathrm{~g})$ has been added and the solution containing the reactants has been heated at $80{ }^{\circ} \mathrm{C}$. Then, we added $0.5 \mathrm{ml}$ of triethanolamine to the solution and we have agitated it during $24 \mathrm{~h}$.

The result has been treated in a big quantity of acetone to obtain a precipitate which has been vacuum-dried at ambient temperature. Finally, the homopolymers have been extracted with methanol during $24 \mathrm{~h}$ on a Soxhlet extractor.

Chitosan-g-PLA Synthesis by Direct Grafting with the Qu and Al Method [9]

The chitosan-g-PLA synthesis by direct grafting is illustrated in the Fig. 2b. The chitosan (3.0 g) was solubilized in $300 \mathrm{ml}$ of $2 \%$ lactic acid. The resulting solution has been put into a reactor $(500 \mathrm{ml})$, agitated with an Ultra-Turrax ${ }^{\circledR}$ homogenizer and purged with nitrogen during $2 \mathrm{~h}$. After that, $9 \mathrm{ml}$ of $85 \% \mathrm{D}$, L lactic acid ( $\sim 7 \mathrm{~g}$ ) have been added, as well as $1 \times 10^{-2}$ mol of p-Toluene Sulfonic Acid (pTSA). The reaction occurred at $80{ }^{\circ} \mathrm{C}$ and lasted $24 \mathrm{~h}$; then the content of the reactor has been poured into a Petri dish, and dried at $50{ }^{\circ} \mathrm{C}$. The homopolymers -or salts- formed during the grafting reaction have been extracted from the films, obtained by extraction with methanol on a Soxhlet extractor.

\section{Thermal Analysis}

The thermal characteristics of the blends were determined by using a Differential Scanning Calorimeter method
Fig. 1 Synthesis of the chitosan-g-PLA copolymers by ROP (a) and by Direct Grafting (b)

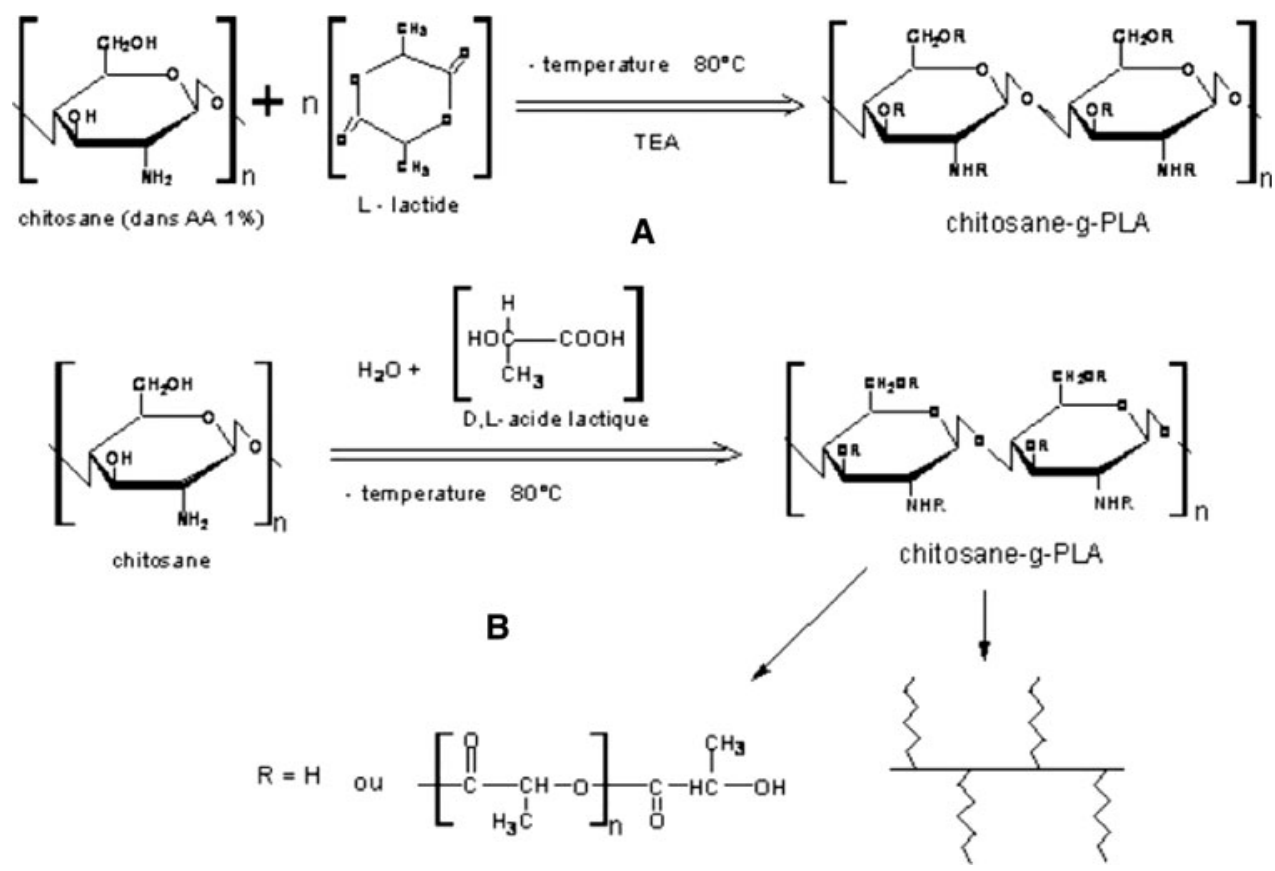


Fig. 2 Chitosan IRTF spectra (a), chit-g-PLA by DG spectra (b) and D, L-lactic acid spectra (c)

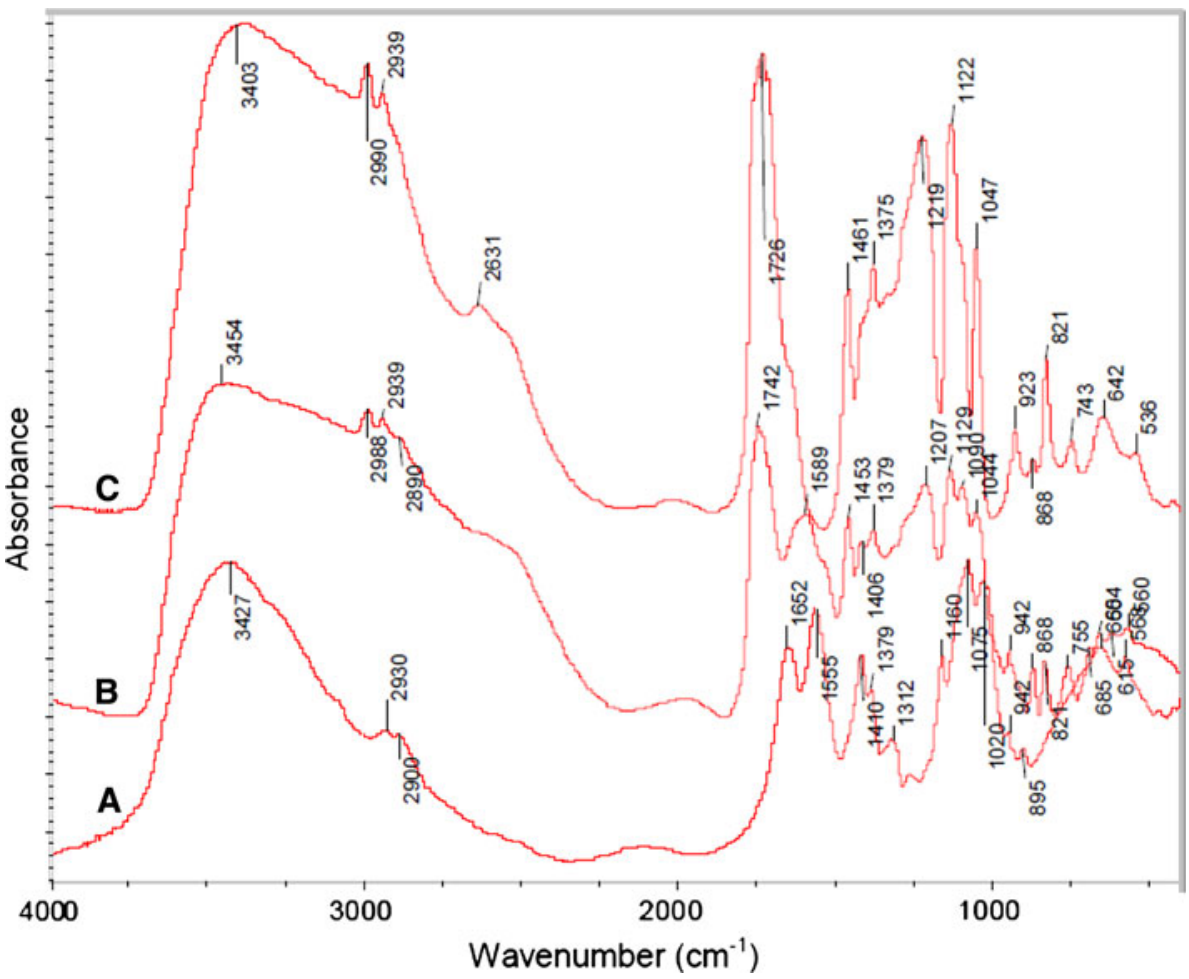

(DSC) (TA instrument-USA) cooled with a liquid nitrogen circulation. Samples (8-10 mg) were cut from a sample specimen after conditioning and placed in sealed aluminium pans. In DSC analysis, the method [11] has been used with minor modification. For each sample, the following thermal cycle was applied: a first scan was made from $30{ }^{\circ} \mathrm{C}$ to $190{ }^{\circ} \mathrm{C}$, then $1 \mathrm{~min}$ at $190{ }^{\circ} \mathrm{C}$, and then the sample was cooled rapidly to $30{ }^{\circ} \mathrm{C}$; it has been kept 3 min at $30{ }^{\circ} \mathrm{C}$, and a second scan up to $250{ }^{\circ} \mathrm{C}$ was made again. The scanning rate was $10^{\circ} \mathrm{C} / \mathrm{min}$, and an empty pan was used as a reference.

\section{IRTF Spectroscopy Analysis}

The samples were prepared in $0.50 \mathrm{~mm}$-thick $\mathrm{KBr}$ pellets, obtained by mixing $3-5 \mathrm{mg}$ of powder films (extra fine) with $200 \mathrm{mg}$ of dried $\mathrm{KBr}$. The IRTF spectra between 4,000 and $400 \mathrm{~cm}^{-1}$ were recorded using a "Protégé 460 . E. S. P. FTIR Spectrometer" device from Nicolet (Madison, WI, USA). All spectra were obtained at ambient temperature with a resolution of $4 \mathrm{~cm}^{-1}$, and 16 scans were carried out for each sample.

\section{Solubility Test and Grafting Efficiency}

The grafting efficiency is calculated with the following equation:

Grafting efficiency $(\%)=(\mathrm{m} 2-\mathrm{m} 1) / \mathrm{m} 3$ where $\mathrm{m} 2, \mathrm{~m} 1$ and $\mathrm{m} 3$ stand respectively for: $\mathrm{m} 2=$ mass of chitosan-g-PLA, $\mathrm{m} 1=$ initial mass of chitosan, $\mathrm{m} 3=$ mass of the initial monomer. For the solubility tests, 10-20 mg of chitosan-g-PLA are dissolved into different solvents, using a magnetic agitation.

\section{Results and Discussion}

Solubility Attempts and Grafting Efficiency

The chitosan's solubility and the solubility of both chitosan-g-PLA copolymers in different solvents are presented in Table 1. We can see that the solubilities of both chit-gPLA copolymers differ from the solubility of pure chitosan. The chitosan is soluble in an acidified aqueous solution, whereas none of the two copolymers are soluble, whatever the tested solvents. Distilled water only caused both copolymers to swell. This difference in solubility confirms that a chemical modification occurred on the chitosan's chain. The grafting efficiencies for both methods are close, around $46 \%$ for direct grafting and $47 \%$ for the ROP method.

\section{IRTF Spectrometry Characterization}

To confirm that PLA grafting on chitosan really occurred, the chitosan IRTF spectra, the L-lactide spectra, the D, 
Table 1 Solubility of the chitosan-g-PLA copolymers obtained by direct grafting (DG) and by ROP

\begin{tabular}{llll}
\hline Solvents & Pure chitosan & $\begin{array}{l}\text { Chit-g-PLA } \\
\text { (DG) }\end{array}$ & $\begin{array}{l}\text { Chit-g-PLA } \\
\text { (ROP) }\end{array}$ \\
\hline Solubility test & Non soluble & Non soluble & Non soluble \\
$\mathrm{H}_{2} \mathrm{O}$ & Very soluble & Non soluble & Non soluble \\
$1 \%$ acetic acid & Very soluble & Non soluble & Non soluble \\
$2 \%$ acetic acid & Non soluble & Non soluble & Non soluble \\
Chloroform & Non soluble & Non soluble & Non soluble \\
Methanol & Non soluble & Non soluble & Non soluble \\
Acetone & Non soluble & Non soluble & Non soluble \\
n-Hexane & & $45.7 \%$ & $46.5 \%$ \\
Grafting efficiency & & & \\
\hline
\end{tabular}

L-lactic acid spectra and both chitosan-grafted-PLA spectra have been recorded and compared. Fig. 2 shows all these IRTF spectra: the D, L-lactic acid and the chitosan-graftedPLA by direct grafting. This figure clearly shows that the chitosan-g-PLA copolymer infrared spectrum has four new peaks at 1,742,1,453,1,589 and $1,207 \mathrm{~cm}^{-1}$. The band at $1,453 \mathrm{~cm}^{-1}$ has been linked to the $\mathrm{CH} 3$ vibrating deformation. The two peaks at 1,589 and $1,207 \mathrm{~cm}^{-1}$ represent respectively the $\mathrm{N}-\mathrm{H}$ and $\mathrm{C}-\mathrm{OH}$ valence vibration. The peak at $1,742 \mathrm{~cm}^{-1}$ represents the $\mathrm{C}=\mathrm{O}$ (ester group) valence vibration. Compared to the $\mathrm{C}=\mathrm{O}$ absorption in the lactic acid, (at $1,720 \mathrm{~cm}^{-1}$ ) the $\mathrm{C}=\mathrm{O}$ band of the grafted chitosan appears at a higher frequency. Thus, this result confirms the copolymerization by direct grafting of the D, L-lactic acid monomer, on the chitosan's chain.
The chitosan IRTF spectra, the L-lactide spectra and the chitosan-g-PLA by ROP spectra are represented in Fig. 3. Compared to the chitosan IR-spectrum, the chitosan-g-PLA copolymer spectra shows three new peaks at 1,734, 1,629 and $1,527 \mathrm{~cm}^{-1}$. The amide I peak in the spectrum of pure chitosan moved from 1,652 to $1,629 \mathrm{~cm}^{-1}$ in grafted chitosan. The amines peak at $1,558 \mathrm{~cm}^{-1}$ in the spectrum of pure chitosan moved to $1,527 \mathrm{~cm}^{-1}$ in grafted chitosan. The small peak at $1,734 \mathrm{~cm}^{-1}$ showing the esters, as well as the strong peak at $1,761 \mathrm{~cm}^{-1}$ showing the L-lactide carbonyl group, confirm both the grafting by the ROP method.

The chitosan crystallinity index decreases clearly, as shown by the IRTF spectra. This is due to PLA grafting. The crystallinity index values are 0.59 for the chitosan; 0.14 for the chit-g-PLA (DG) and 0.21 for the chit-g-PLA (ROP), see Table 2.

\section{Thermal Properties}

Both chitosan-g-PLA copolymers thermal properties are different from those from pure chitosan (Figs. 4 and 5). Figure 3 shows the DSC thermograms for the grafted copolymers and for pure chitosan obtained after the first heating. The two chitosan grafted copolymers don't show any endothermic peak, while pure chitosan has a high endothermic peak around $91{ }^{\circ} \mathrm{C}$, due to the evaporation of the water present in the chitosan matrices. This result could indicate that grafting decreases the number of free- $\mathrm{NH} 2$ and free-OH, which are responsible for the chitosan's hygroscopy.
Fig. 3 Chitosan IR spectrum (a), chit-g-PLA by ROP spectrum (b) and L-lactide spectrum (c)

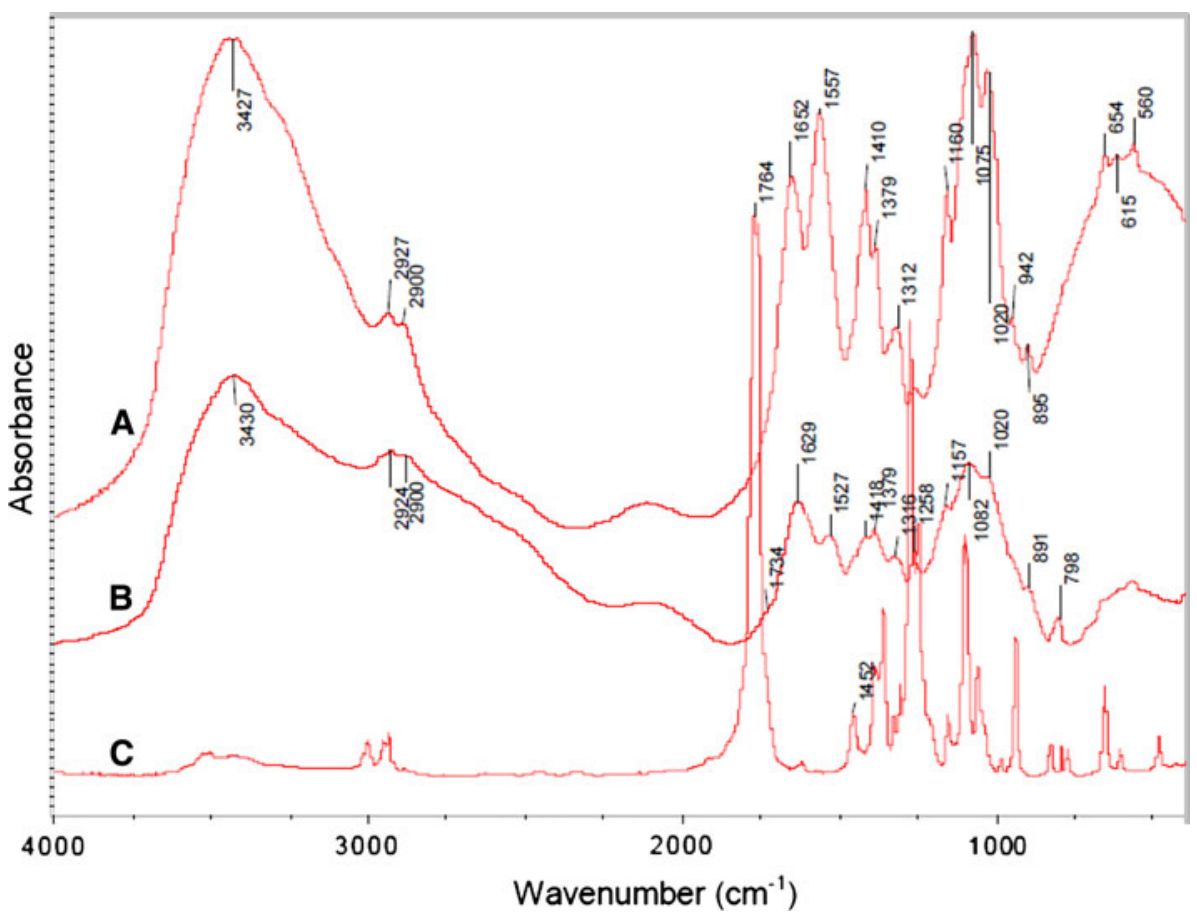


Table 2 Thermal qualities and crystallinity index for the chitosan and for the chit-g-PLA (DG) and chit-g-PLA (ROP) copolymers

\begin{tabular}{llll}
\hline Characteristics & $\begin{array}{l}\text { Pure } \\
\text { chitosan }\end{array}$ & $\begin{array}{l}\text { Chit-g-PLA } \\
\text { (DG) }\end{array}$ & $\begin{array}{l}\text { Chit-g-PLA } \\
\text { (ROP) }\end{array}$ \\
\hline $\begin{array}{l}\text { Thermal qualities: } \\
\text { Endothermic peak }\end{array}$ & $91{ }^{\circ} \mathrm{C}$ & & \\
Glass transition temp. (Tg) & $202{ }^{\circ} \mathrm{C}$ & $144{ }^{\circ} \mathrm{C}$ & $149{ }^{\circ} \mathrm{C}$ \\
Thermal degradation Temp. & $253{ }^{\circ} \mathrm{C}$ & $204{ }^{\circ} \mathrm{C}$ & $201{ }^{\circ} \mathrm{C}$ \\
Crystallinity index (IRTF) & 0.59 & 0.14 & 0.21 \\
\hline
\end{tabular}

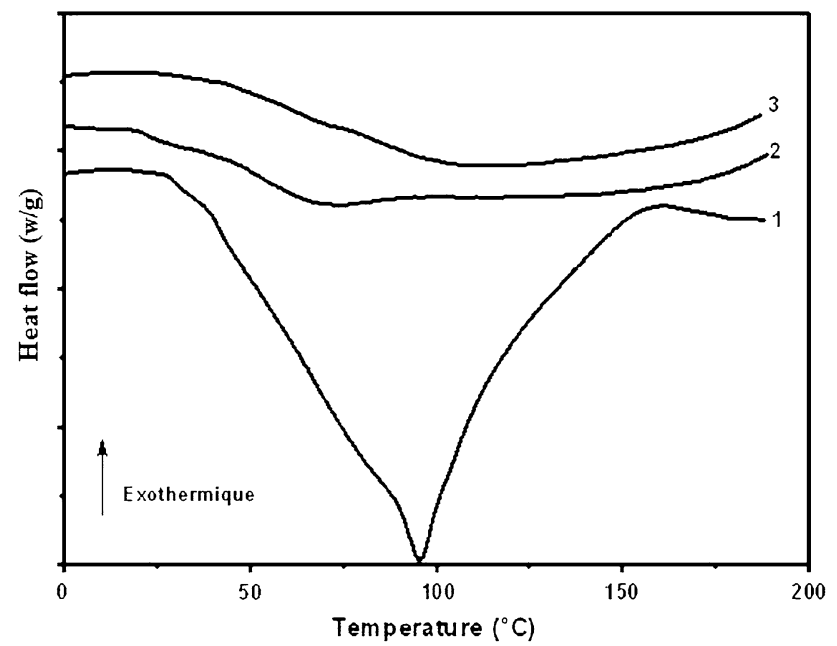

Fig. 4 DSC Thermograms obtained after the first sweep for pure chitosan (1), for chit-g-PLA by DG copolymer (2) and for chit-g-PLA by ROP copolymer (3)

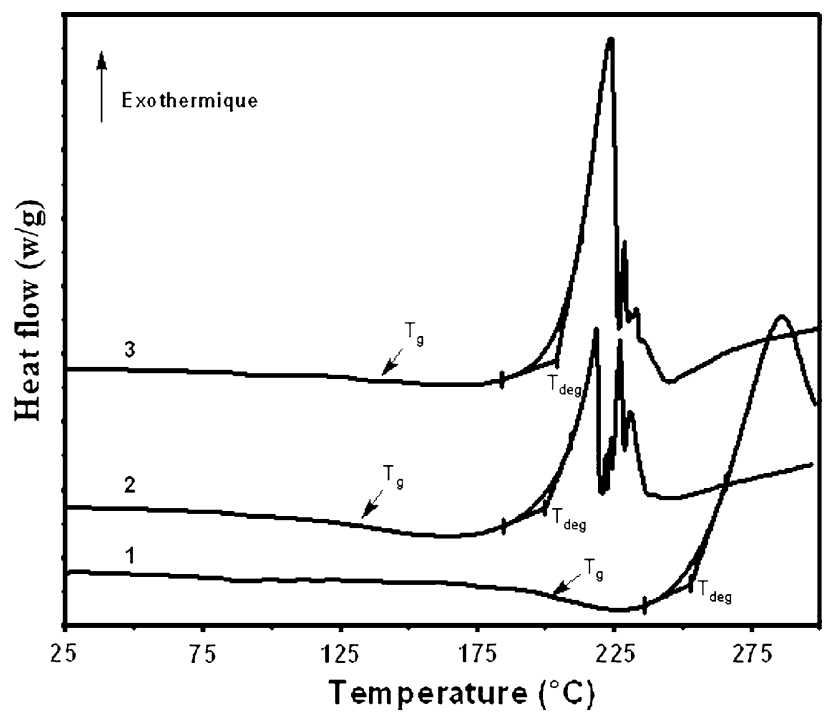

Fig. 5 DSC Thermograms obtained after the second sweep for pure chitosan (1), for chit-g-PLA by DG copolymer (2) and for chit-g-PLA by ROP copolymer (3)
During the second DSC sweep (Fig. 5), the thermal degradation of pure chitosan occurs at a highest temperature than the one for grafted chitosan. That could indicate that grafts thermal degradation occurs before the thermal degradation of the main chitosan's chain. This result goes in the same way that what was showed in [12]: indeed they noticed that the thermal degradation rate related to grafted chitosan copolymer is far higher than the one related to pure chitosan. The thermal degradation temperatures $\left(\mathrm{T}_{\mathrm{deg}}\right)$ for chitosan and grafted chitosan (Table 2) are ordered as follow:

$\mathrm{T}_{\text {deg }}$ for chitosan $>\mathrm{T}_{\text {deg }}$ for chit-g-PLA by $\mathrm{DG}>\mathrm{T}_{\text {deg }}$ for chit-g-PLA by ROP.

Figure 5 shows that the Glass Transition Temperature $\mathrm{Tg}$ for the chitosan is $202{ }^{\circ} \mathrm{C}$, and those for the two copolymers are respectively $144{ }^{\circ} \mathrm{C}$ for direct grafting and $149^{\circ} \mathrm{C}$ for the ROP method. A lower $\mathrm{Tg}$ for grafted chitosan could be due to the suppression of some hydrogen bonds between the chitosan's chains. In other words, PLA grafting on chitosan increases chitosan's chain flexibility.

\section{Conclusion}

PLA grafting on chitosan has been successfully prepared with two different methods: direct grafting (DG) method and the ROP method.

With the conditions used to conduct this study, the grafting efficiencies for both methods were similar (Table 2). PLA grafting on a chitosan's chain has been confirmed by the IRTF analysis. The thermal properties showed that the copolymerization of PLA on a chitosan's chain by direct grafting is more thermostable than the one obtained by the ROP method.

From an economic point of view, direct grafting is more suitable for a large industrial scale, because the D, L-lactic acid is far less expensive than the L-lactide. Our method of grafting is more efficient than the one used by [9]. This efficiency is highlighted by the esters' peak in the IR spectra, which doesn't exist in their survey. Besides, the solubility test proved that grafted chitosan is neither soluble in the organic solvents of the PLA nor in dilute acid which is a good solvent of pure chitosan. Therefore, due to this insolubility, the PLA-grafted-chitosan will not be used for the next studies on compatibilization of the chitosan/ PLA solution.

Open Access This article is distributed under the terms of the Creative Commons Attribution Noncommercial License which permits any noncommercial use, distribution, and reproduction in any medium, provided the original author(s) and source are credited. 


\section{References}

1. Hsu SC, Don TM, Chiu WY (2002) Synthesis J Appl Polym Sci 86:3047

2. Yazdani-Pedram M, Lagos Retuert A (2002) Polym Bul 48:93

3. Ouchi T, Nishizawa H, Ohya Y (1998) Polym 39:5171

4. Kolhe P, Kannan M R (2003) Biomacromol 4:173

5. Hu Y, Jiang H, Xu C, Wang Y, Zhu K (2005) Carbohyd Polym 61:472
6. Huang M, Fang Y (2006) Biopolym 81:160

7. Prashanth KVH, Tharanathan RN (2003) Carbohyd Polym $54: 343$

8. Don TM, King CF, Chiu WY (2002) J Appl Polym Sci 86:3057

9. Qu X, Wirsén A, Albertson A (1999) J Appl Polym Sci 74:3186

10. Kim JY, CS Ha, Jo NJ (2002) Polym Int 51:1123

11. Sakurai K, Maegawa T, Takahashi T (2000) Polym 41:7051

12. Ding WQ, Lian R, Samuels J, Polk MB (2003) Polymer 44:547 